Pratama L., Fardhosseini S., Dossick C., Habibnezhad M., Jebelli H. and Lee H. (2020). "BIM-GIS implementation for rebuilding after disaster: a critical evaluation" In: Proc. 37th CIB W78 Information Technology for Construction Conference (CIB W78), São Paulo, Brazil, pp. 112-120. DOI: http://dx.doi.org/10.46421/2706-6568.37.2020.paper009

\title{
BIM-GIS IMPLEMENTATION FOR REBUILDING AFTER DISASTER: A CRITICAL EVALUATION
}

\author{
Lucky A. Pratama ${ }^{1}$, Mohammad S. Fardhosseini ${ }^{2}$, Carrie S. Dossick ${ }^{3}$, Mahmoud \\ Habibnezhad $^{4}$, Houtan Jebelli ${ }^{5}$, and Hyun W. Lee ${ }^{6}$
}

\begin{abstract}
The emergence of new technologies in the architecture, engineering, and construction (AEC) industries allow decision-makers to gain a great deal of control over every stage of their projects. However, due to the dynamic and fragmented nature of the AEC industry, developing an effective data exchange between AEC professionals and the construction industries is challenging and requires a major effort for bilateral integration. This challenge calls for an integrated approach across several commonly used platforms. As a representative example, this article discusses the viability of integrating Building Information Modeling and Geographic Information Systems (BIM-GIS) to solve problems in the built environment, such as the data-driven disaster-mitigation process. By thoroughly reviewing previous studies, this paper aims to identify the ongoing theme of BIMGIS integration and highlight gaps in the literature. As a result, the paper presents several recommendations to address these gaps and improve data exchange in the AEC industry.
\end{abstract}

Keywords: BIM-GIS, data exchange, disaster mitigation.

\section{INTRODUCTION}

The fragmented and dynamic nature of the architecture, engineering, and construction (AEC) industries makes it challenging to effectively achieve robust data communication between industry professionals and the construction fields (Isikdag and Zlatanova 2009). However, new technologies offer professionals the chance to obtain much better control over their ongoing projects.

Integration and interoperability between emerging technologies are critical to achieve a better, more efficient outcome. One example of effective data exchange is the integration of Building Information Modeling (BIM) and Geographical Information Systems (GIS;(Song et al. 2017). BIM has been the tool that bridges the interoperability gap between different disciplines involved in a project. Meanwhile, GIS is predominantly used as a tool to extract the geographical information of an area. Its use is not restricted to the AEC industry, so GIS has been used in relatively diverse disciplines, including construction, disaster mitigation, and forest management (Isikdag and Zlatanova 2009). Others include agriculture and natural resources, community and regional planning, and infrastructure and urban facilities management.

PhD Candidate, University of Washington, Seattle, USA, pragungl@uw.edu

PhD Candidate, University of Washington, Seattle, USA, sadrafh@uw.edu

Professor, P University of Washington, Seattle, USA, cdossick@uw.edu

Postdoctoral Researcher, Pennsylvania State University, University Park, USA, mh.habibnezhad@gmail.com

Assistant Professor, Pennsylvania State University, University Park, USA, jebelli.houtan@gmail.com

Associate Professor, University of Washington, Seattle, USA, hyunwlee@uw.edu 
While each platform has different uses, incorporating the data generated by both platforms could yield an extremely detailed and comprehensive image of a project. This process can help AEC professionals address several complexities in their industry, from managing the flow of information between project stakeholders to micromanaging elements of an AEC project. For instance, the BIM-GIS integration can be useful to a facility manager overseeing the location of various assets, as well as managing the energy assessment for each asset (Zhang et al. 2009; Fosu et al. 2015; Song et al. 2017).

With the increased interest in the integration of BIM and GIS, it is critical to map how far current knowledge has progressed. To that end, this study aims to address some of the potential applications of BIM and GIS integration and any gaps in knowledge in the BIM-GIS literature. More specifically, the objectives of the paper include (1) to identify current trends in BIM and GIS research; (2) to report on existing knowledge surrounding the integration of BIM and GIS; (3) to provide a framework for implementation of BIM and GIS in real-world scenarios; and (4) to present recommendations for future studies.

In addition, this paper provides a critical evaluation of BIM-GIS integration for disaster mitigation. This theme was chosen because of the systems' capacities to complement each other. In a disaster-mitigation situation, GIS could provide information on terrain conditions of the disaster area. Meanwhile, BIM would provide detailed information on the buildings and built environment in the area.

By identifying these research trends, solutions can be proposed to pave the way for designing an advanced AEC data exchange.

\section{RESEARCH TRENDS IN BIM-GIS INTEGRATION}

There have been several studies on BIM-GIS integration over the past years. Researchers identified trends in both technical and applied aspects. To identify these trends, a digital search query of the ASCE library and Automation in Construction was performed. The query yielded 274 publications dated from 2007 to 2018. To examine this trend, 33 publications were selected for review. The analysis yielded several major themes: (1) BIM as a representation and information management tool; (2) data exchanges between platforms in BIM-GIS integration; and (3) GIS for disaster-management tools (Table 1).

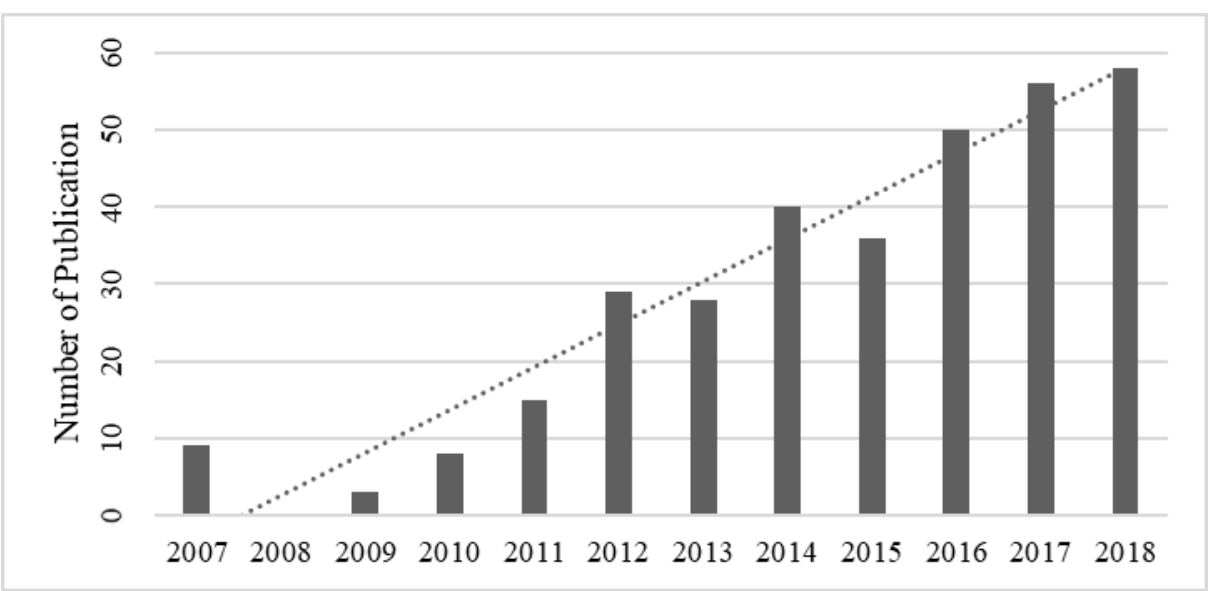

Figure 1. BIM-GIS integration publications between 2007-2018 
Table 1. BIM-GIS publication themes from 2007 to 2018

\begin{tabular}{|c|c|c|}
\hline Themes & Author & Year \\
\hline \multirow{2}{*}{ Approaching BIM-GIS technical challenge } & Hijazi et al. & 2010 \\
\hline & Kang and Hong & 2016 \\
\hline Automatic data translation from BIM to GIS & Isikdag and Zlatanova & 2009 \\
\hline Benefits of a successful BIM-GIS Implementation & Zhang et al. & 2009 \\
\hline Benefits of BIM-GIS Implementation & Fosu et al. & 2015 \\
\hline BG-ETL software architecture & Kang and Hong & 2017 \\
\hline BIM-GIS data exchanges & Ma and Ren & 2017 \\
\hline \multirow{11}{*}{ BIM-GIS in disaster mitigation } & Lapierre and Cote & 2007 \\
\hline & Dollner and Hagedorn & 2007 \\
\hline & Isikdag et al. & 2008 \\
\hline & Chen et al. & 2014 \\
\hline & Amirebrahimi et al. & 2015 \\
\hline & Tashakkori et al. & 2015 \\
\hline & Deng et al. & 2016 \\
\hline & Wu and Zhang & 2016 \\
\hline & $\mathrm{Xu}$ et al. & 2016 \\
\hline & Teo and Cho & 2016 \\
\hline & Hu et al. & 2016 \\
\hline \multirow{6}{*}{ BIM-GIS technical challenge } & El Meouche et al. & 2013 \\
\hline & Dollner and Hagedorn & 2007 \\
\hline & Isikdag and Zlatanova & 2009 \\
\hline & de Laat and van Berlo & 2011 \\
\hline & Mignard and Nicolle & 2014 \\
\hline & Karan and Irizarry & 2015 \\
\hline \multirow{2}{*}{ Compromises on Current BIM-GIS integration } & Song et al. & 2017 \\
\hline & Ma and Ren & 2017 \\
\hline Data exchange between BIM and GIS & Yuan and Shen & 2010 \\
\hline IFC and City GML role in BIM-GIS integration & Groger and Plumer & 2012 \\
\hline Multiple benefits of BIM-GIS integration & Amirebrahimi et al. & 2016 \\
\hline \multirow{11}{*}{ The importance of data integrity in data exchange } & Dollner and Hagedorn & 2007 \\
\hline & Isikdag and Zlatanova & 2009 \\
\hline & El Mekawy and Osmtman & 2010 \\
\hline & El Mekawy et al. & 2011 \\
\hline & de Laat and van Berlo & 2011 \\
\hline & El Mekawy et al. & 2012 \\
\hline & El Meouche et al. & 2013 \\
\hline & Mignard and Nicolle & 2014 \\
\hline & Chen et al. & 2014 \\
\hline & Kang and Hong & 2015 \\
\hline & Fosu et al. & 2015 \\
\hline
\end{tabular}

Researchers found that disaster mitigation is one of the more popular themes in recent publications, whereas other publications also partially covered disaster management. 
Lucky Pratama, Mohammad Fardhosseini, Carrie S. Dossick, Mahmoud Habibnezhad, Houtan Jebelli, and Hyun W. Lee

\section{KEY STRENGTHS OF BIM AND GIS}

\subsection{BIM as a Representation and Information Management Tool}

BIM refers to the first building-depiction system targeting both digital transformation and visualization of building components (Eastman et al., 1974). National BIM Standards Purpose (NBIMS 2006) defines BIM as a digital representation of a facility that can display its physical and functional characteristics simultaneously. Although Van Nederveen and Tolman (Nederveen and Tolman 1992) first suggested the term "BIM" in 1992, it did not become popular until the early 2000s, when Autodesk, Bently, Graphisoft, and CAD applications became pervasive (Autodesk Inc. 2003). Furthermore, as the level of development and detail plays a critical role in BIM visualizations, the progress of BIM models from the lowest 2D Level of Development (LOD) to the highest BIM LOD (with 3D models and related non-geometric information) started to accelerate (Bedrick 2013; Fai and Rafeiro 2014).

BIM refers to the first building-depiction system targeting both digital transformation and visualization of building components (Eastman et al., 1974). National BIM Standards Purpose (NBIMS 2006) defines BIM as a digital representation of a facility that can display its physical and functional characteristics simultaneously. Although Van Nederveen and Tolman (Nederveen and Tolman 1992) first suggested the term "BIM" in 1992, it did not become popular until the early 2000s, when Autodesk, Bently, Graphisoft, and CAD applications became pervasive (Autodesk Inc. 2003). Furthermore, as the level of development and detail plays a critical role in BIM visualizations, the progress of BIM models from the lowest 2D Level of Development (LOD) to the highest BIM LOD (with 3D models and related non-geometric information) started to accelerate (Bedrick 2013; Fai and Rafeiro 2014).

\subsection{BIM as a Multi-dimensional Model}

BIM is mostly used in large and complex projects because it integrates the management of several project dimensions (e.g., cost, time, and environmental influences), in addition to the 3D representation of the building. Because of these added dimensions, BIM introduced the concept of 4D, 5D, 6D, and 7D BIM, in which the dimensions of time, cost, sustainable components, and facility-management lifecycle, respectively, are considered (Ikerd 2010; Smith 2014). The various dimensions of BIM require project stakeholders to work consistently and productively, so each dimension can be managed efficiently (Ponting et al. 2005; Succar 2009).

The capacity to run multidimensional BIM modeling allows for the creation of a centralized data-management system for building information. Since cost, quantity, schedule, and other elements are integrated into the model, stakeholders can then retrieve consistent inforication throughout the building lifecycle.

\subsection{GIS for Topography Data Management}

Augmenting BIM, GIS focuses on the management of topographic data and human-made phenomena based in a geographic reference system (Fosu et al. 2015). The system should be compatible with all digitized spatial or geographical data (Huxhold 1991). GIS is essentially an information system that includes topographic data and human-made phenomena grounded in a geographic reference system (Fosu et al. 2015). A GIS database contains operations for spatially referenced data, which are applicable in 
various diverse spatially grounded disciplines, such as facility management, agriculture, natural-resource management, public health, and business (Berry 1996), among others. With its versatility as a geographic database system, its main advantages include (Lin et al. 1997; Lemer 1998; Valcik and Huesca-dorantes 2002; Zhang et al. 2009): (1) spatialanalysis functions supporting 3D measurements; (2) facilitation of the identification of buildings; (3) enabling users to analyze and predict the remaining service life; and (4) assessing investments based on GIS multicriteria- evaluation support systems.

\section{DATA EXCHANGE BETWEEN BIM-GIS PLATFORMS}

In terms of data structure, BIM and GIS are considered stand-alone systems. Each has a specialized file format that stores only necessary information, such as the BIM file format, which contains information on building elements and materials. Attempting to develop a file format that encompasses both systems would be too complex because the information must be mapped across each system. In addition, each BIM's and GIS's development mean the respective system's file structure is always updated (Andrews 2019).

Many researchers have investigated how data exchanges between BIM and GIS platforms can be executed. There have been several approaches: (1) BIM to GIS data export; (2) GIS to BIM data export; or (3) BIM and GIS data export to a third platform known as City Geography Markup Language, or City GML (Ma and Ren 2017). City GML is the common standard used in GIS, whereas Industrial Foundation Class (IFC) performs the same role in BIM, which is the leading standard for BIM-GIS integration (Hijazi et al. 2011; Gröger and Plümer 2012; Cheng et al. 2013). However, this conventional approach inadvertently led to the misalignment of data between the BIMGIS system (Yuan and Sheng 2010). In this respect, Isikdag and Zlatanova (2009a) observed that due to the conceptual misalignment of the BIM-GIS systems, viable data conversion could not be achieved by transferring one dataset to the other one. This limitation can be addressed by using models that not only support both IFC and City GML but also allow bi-directional conversion of data between the two, such as the Unified Building Model (UBM;(El-Mekawy and Östman 2010; El-Mekawy et al. 2011, 2012). To this end, a two-part transformation of the geometric and semantic datasets is required.

In addition to the UBM, there are approaches studied by other researchers to address BIM-GIS technical challenges, including web technology, a semantic-based multirepresentation approach, prototype implementation, and a resources-description framework. For example, a study suggested a web platform as a transition between the GIS and BIM systems that visualizes both models (Döllner and Hagedorn 2007). Meanwhile, another study found an approach using a semantic web format allows researchers to query multiple models (Karan et al. 2016).

Researchers also developed programs such as Geo BIM (Berlo and Laat 2011) and the Urban Information Modeling extension to manage facilities (Mignard and Nicolle 2014). Another study introduced a prototype displaying the procedure of interoperability based on existing software (El Meouche et al. 2013). Finally, a number of researchers tried to shed light on this gap by demonstrating conceptual frameworks to transition automatically from BIM to GIS (Isikdag and Zlatanova 2009; Chen et al. 2014). The dataintegration solution presented by previous research seemed to focus mostly on a conceptual level. Even though the solutions promised interoperability between them systems, case studies are necessary to investigate their applicability in a real-world 
Lucky Pratama, Mohammad Fardhosseini, Carrie S. Dossick, Mahmoud Habibnezhad, Houtan Jebelli, and Hyun W. Lee

scenario. Therefore, the next part of this study presents several cases showing how integration can be implemented.

\section{BIM-GIS UTILIZATION FOR EMERGENCY AND DISASTER RESPONSE}

\subsection{BIM-GIS-Based Emergency Navigation System}

Five articles were reviewed on BIM-GIS integration that focused on emergency indooroutdoor navigation systems (Tashakkori et al. 2015; Hu et al. 2016; Teo and Cho 2016; $\mathrm{Wu}$ and Zhang 2016; Xu et al. 2016). One study combined a building's IFC data with the surrounding environmental data from a GIS to propose an indoor, emergency spatial model (Tashakkori et al. 2015). According to the study, the model serves to improve a responder's awareness of the situation indoors. It is expected that by improving situational awareness, responders could identify the best rescue route in the event of an emergency.

Another study determined a practical algorithm for an optimal evacuation route in a crowded situation (Xu et al. 2016). CAD-BIM data was incorporated into the GIS dataset to develop an algorithm that created an optimized evacuation route inside a building.

Since there has been interest in developing a BIM-GIS-based system to generate an evacuation route, one study sought to shed light on the issue and researchers summarized their contributions as follows (Teo and Cho 2016): (1) developing a framework considering BIM and the Multi-purpose Geometric Network Model (MGNM), based in IFC and indoor networks to display a novel approach to determining the indoor network from IFC automatically; (2) connecting the entrances of buildings and streets by transferring arcs based on indoor-outdoor networks from on a given scheme; and (3) developing a route planning system that is coarse to fine based on both city and building scales.

\subsection{Integration of BIM-GIS into Disaster Response Systems}

BIM models can also be added to map and terrain data from GIS databases to generate a large dataset housed in an Open Geospatial Consortium (OGC) web service. In a disaster, these web services can be used for better disaster management (e.g., selection of sites or designing a field hospital;(Döllner and Hagedorn 2007; Lapierre and Cote 2008; Ma and Ren 2017). BIM-GIS integration could also support construction phases, including disaster-related ones. In general, the advantages of BIM-GIS applications to the built environment are as follows (Song et al. 2017): (1) using data with different spatial scales to discover issues in the built environment; (2) providing comprehensive information on geometry and material of building components by integrating BIM; and (3) enhancing the effectiveness and performance of AEC projects.

\section{GAPS IDENTIFIED IN BIM-GIS INTEGRATION}

Even with the general success of BIM-GIS integration, some uncertainties remain. Most publications that studied their integration did not take full advantage of an independent BIM and GIS. For instance, sometimes, just the visualization of GIS was used, whereas GIS by itself can be used for any geographic decisions with visual content and geospatial modeling. In most occasions, the spatial and spatiotemporal analysis was not explored. 
In the publications, some problems with the BIM's generally viable applications and advantages were also discovered. Even though BIM provides geometric and semantic information, the study found that user requirements for information in AEC projects were still lacking. This issue has become more important in recent years as more users are seeking out BIM for the examination of issues such as quality, time, and cost. Another component, such as LOD, is also underused; it has not been considered a spatiotemporal attribute in the integration procedure for the decision-making process.

Notably, in spite of the fact that these elements serve critical functions in GIS, little attention has been given to both spatial and spatiotemporal statistical modeling of GIS and a multidimensional BIM to address knowledge. Unlike construction, the spatiotemporal modeling has been used in several domains (e.g., social science, atmospheric, hydrology, geology, etc.). Spatiotemporal statistical modeling in construction could be used for analyzing different aspects of projects, including quality, progress, safety, contract, coordination, and, especially cost. Considered simultaneously are achieving accuracy and dynamic financial-resource allocation. These are of critical analytical help in the use of holistic, data-driven spatiotemporal modeling, especially examining multiple projects.

Interestingly, there is an enormous potential for a more precise, flexible, or broader use of BIM with GIS integration. For example, it is possible to conduct spatiotemporal statistical modeling in a post-disaster area. This element can be used to analyze the allocation of financial resources in a restoration effort. It would be more efficient than a conventional damage-assessment method, especially if the disaster occurred over a large area.

\section{CONCLUSION}

Despite the extensive topics covered by the literature on BIM-GIS integration, we note here several key areas that have not been fully explored. The integration of BIM-GIS mostly results in compromised data exchange between them. In addition, future studies should address spatiotemporal statistical modeling to measure various aspects of construction projects. The literature review also highlighted several potential uses of BIM-GIS integration studies going forward, including a technology hypothesis, a scientific hypothesis, and a data-source hypothesis. Successful implementation of the hypotheses lies in the extensive data-driven spatiotemporal modeling of AEC projects. The combination of objective analysis and decision making characteristic of BIM-GIS is expected to satisfy the AEC industry's need for future applications.

\section{REFERENCES}

Andrews C (2019) 5 Myths and 5 Realities of BIM-GIS Integration. In: ArcGIS Blog. 5 Myths and 5 Realities of BIM-GIS Integration

Autodesk Inc. (2003) Building Information Modelling; White Paper. San Rafael, CA, USA

Bedrick J (2013) A level of development specification for BIM processes. AECbytes Viewpoint, 68

Berlo L Van, Laat R De (2011) Integration of BIM and GIS: The development of the CityGML GeoBIM extension. In: Advances in 3D geo-information sciences. Springer

Berlin Heidelberg, pp 211-225

Berry J (1996) GIS evolution and future trends. GeoWorld Magazine 
Lucky Pratama, Mohammad Fardhosseini, Carrie S. Dossick, Mahmoud Habibnezhad, Houtan Jebelli, and Hyun W. Lee

Chen L, Wu C, Shen T, Chou C (2014) The application of geometric network models and building information models in geospatial environments for fire-fighting simulations. Computers, Environment and Urban Systems 45:1-12. doi: 10.1016/j.compenvurbsys.2014.01.003

Cheng J, Deng Y, Du Q (2013) Mapping between BIM Models and 3D GIS City Models of Different Levels of Detail. Automation in Construction 30-31

Döllner J, Hagedorn B (2007) Integrating urban GIS, CAD, and BIM data by servicebased virtual 3D city models. In: Urban and Regional Data Management. CRC Press, London, pp 157-160

El-Mekawy M, Östman A (2010) Semantic Mapping: An Ontology Engineering Method for Integrating Building Models in IFC and CityGML. In: 3rd ISDE DIGITAL EARTH SUMMIT

El-Mekawy M, Östman A, Hijazi I (2012) An Evaluation of IFC-CityGML Unidirectional Conversion. International Journal of Advanced Computer Science and Applications 3:

El-Mekawy M, Östman A, Shahzad K (2011) Towards Interoperating CityGML and IFC Building Models: A Unified Model Based Approach. In: Advances in 3D GeoInformation Sciences. pp 73-93

El Meouche R, Rezoug M, Hijazi I (2013) Integrating and managing BIM in gis, software review. International Archives of the Photogrammetry, Remote Sensing and Spatial Information Sciences - ISPRS Archives 2:31-34

Fai S, Rafeiro J (2014) Establishing an appropriate level of detail (LOD) for a building information model (BIM) - West Block, Parliament Hill, Ottawa, Canada. ISPRS Annals of the Photogrammetry, Remote Sensing and Spatial Information Sciences 2:123-130

Fosu R, Cory C, Suprabhas J, Rathore Z (2015) Integration of Building Information Modeling ( BIM ) and Geographic Information Systems ( GIS ) - a literature review and future needs .

Gröger G, Plümer L (2012) CityGML - Interoperable semantic 3D city models. 71:12-33. doi: $10.1016 /$ j.isprsjprs.2012.04.004

Hijazi I, Ehlers M, Zlatanova S, Adolphi T (2011) Initial Investigations for Modeling Interior Utilities Within 3D Geo Context: Transforming IFC-Interior Utility to CityGML / UtilityNetworkADE. doi: 10.1007/978-3-642-12670-3

$\mathrm{Hu}$ K, Chen M, Duan SX, et al (2016) Research on Management System of Disaster Prevention and Relief Based on Building Information Modeling. In: International Conference on Information System and Artificial Intelligence (ISAI). pp 232-235

Huxhold WE (1991) An introduction to urban geographic information systems. Oxford University Press

Ikerd W (2010) Who's Using BIM, Trends, and drivers affecting structural engineers. Structural Engineering \& Design, April

Isikdag U, Zlatanova S (2009) Towards Defining a Framework for Automatic Generation of Buildings in CityGML Using Building Information Models Towards defining a framework for automatic generation of buildings in CityGML using Building Information Models. doi: 10.1007/978-3-540-87395-2

Karan EP, Irizarry J, Asce M, Haymaker J (2016) BIM and GIS Integration and Interoperability Based on Semantic Web Technology. 30:1-11. doi: 10.1061/(ASCE)CP.1943-5487.0000519.

Lapierre A, Cote P (2008) Using Open Web Services for urban data management: A testbed resulting from an OGC initiative for offering standard CAD / GIS / BIM services. 381-394 
Lemer A. (1998) Progress toward integrated infrastructure-assets-management systems: GIS and beyond. 7-24

Lin H, Wan Q, Li X, et al (1997) GIS-based multicriteria evaluation for investment environment. 24:403-414

Ma Z, Ren Y (2017) Integrated Application of BIM and GIS : An Overview. Procedia Engineering 196:1072-1079. doi: 10.1016/j.proeng.2017.08.064

Mignard C, Nicolle C (2014) Merging BIM and GIS using ontologies application to urban facility management in ACTIVe3D. Computers in Industry 65:1276-1290. doi: 10.1016/j.compind.2014.07.008

Nederveen GA Van, Tolman FP (1992) Modelling multiple views on buildings * ${ }^{\text {. 1:215- }}$ 224

Pavan A, Daniotti B, Re Cecconi F, et al (2014) INNOVance: Italian BIM Database for Construction Process Management. doi: 10.1061/9780784413616.080

Ponting M, Lee A, Wu S (2005) $\mathrm{nD}$ modelling road map: A vision for $\mathrm{nD}$ - Enabled construction

Singh V, Gu N, Wang X (2011) Automation in Construction A theoretical framework of a BIM-based multi-disciplinary collaboration platform. 20:134-144. doi: 10.1016/j.autcon.2010.09.011

Smith P (2014) BIM \& the 5D Project Cost Manager. 119:475-484. doi: 10.1016/j.sbspro.2014.03.053

Song Y, Wang X, Tan Y, et al (2017) Trends and Opportunities of BIM-GIS Integration in the Architecture, Engineering and Construction Industry: A Review from a Spatio-Temporal Statistical Perspective. 1-32. doi: 10.3390/ijgi6120397

Succar B (2009) Building information modelling framework: A research and delivery foundation for industry stakeholders. Automation in Construction 18:357-375. doi: 10.1016/j.autcon.2008.10.003

Tashakkori H, Rajabifard A, Kalantari M (2015) A new 3D indoor / outdoor spatial model for indoor emergency response facilitation. Building and Environment 89:170182. doi: 10.1016/j.buildenv.2015.02.036

Teo T, Cho K (2016) Advanced Engineering Informatics BIM-oriented indoor network model for indoor and outdoor combined route planning. Advanced Engineering Informatics 30:268-282. doi: 10.1016/j.aei.2016.04.007

Valcik NA, Huesca-dorantes P (2002) Building a GIS Database for Space and Facilities Management. 53-61

Wu B, Zhang S (2016) INTEGRATION OF GIS AND BIM FOR INDOOR GEOVISUAL ANALYTICS. XLI:455-458. doi: 10.5194/isprsarchives-XLI-B2-455-2016

Xu M, Hijazi I, Mebarki A, Meouche R El (2016) Indoor guided evacuation: TIN for graph generation and crowd evacuation. Geomatics, Natural Hazards and Risk 7:4756. doi: 10.1080/19475705.2016.1181343

Yuan Z, Sheng GQP (2010) Using iFC standard to integrate BIM models and GIS. In: International Conference on Construction and Real Estate Management, Vols 1-3. Beijing, China, pp 224-229

Zhang X, Arayici Y, Wu S, et al (2009) Integrating BIM and GIS for large - scale facilities asset management : a critical review 